\title{
Some new features of electron density irregularities over SHAR during strong spread $\mathbf{F}$
}

\author{
S. Raizada and H. S. S. Sinha \\ Physical Research Laboratory, Navrangpura, Ahmedabad - 380 009, India \\ Received: 21 April 1999 / Revised: 22 September 1999 / Accepted: 4 October 1999
}

\begin{abstract}
An RH-560 rocket flight was conducted from Sriharikota rocket range (SHAR) $\left(14^{\circ} \mathrm{N}, 80^{\circ} \mathrm{E}\right.$, dip latitude $5.5^{\circ} \mathrm{N}$ ) to study electron density and electric field irregularities during spread $\mathrm{F}$. The rocket was launched at 2130 local time (LT) and it attained an apogee of $348 \mathrm{~km}$. Results of electron density fluctuations are presented here. Two extremely sharp layers of very high electron density were observed at 105 and $130 \mathrm{~km}$. The electron density increase in these layers was by a factor of 50 in a vertical extent of $10 \mathrm{~km}$. Large depletions in electron density were observed around 175 and $238 \mathrm{~km}$. Both sharp layers as well as depletions were observed also during the descent. The presence of sharp layers and depletions during the ascent and the descent of the rocket as well as an order of magnitude less electron density, in $150-300 \mathrm{~km}$ region during the descent, indicate the presence of strong large-scale horizontal gradients in the electron density. Some of the valley region irregularities $(165-178 \mathrm{~km})$, in the intermediate scale size range, observed during this flight, show spectral peaks at $2 \mathrm{~km}$ and can be interpreted in terms of the image striation theory suggested by Vickrey et al. The irregularities at $176 \mathrm{~km}$ do not exhibit any peak at kilometer scales and appear to be of new type. The growth rate of intermediate scale size irregularities, produced through generalized Rayleigh Taylor instability, was calculated for the 200$330 \mathrm{~km}$ altitude, using observed values of electron density gradients and an assumed vertically downward wind of $20 \mathrm{~ms}^{-1}$. These growth rate calculations suggest that the observed irregularities could be produced by the gradient drift instability.
\end{abstract}

Key words: Ionosphere (equatorial ionosphere; ionospheric irregularities) - Radio science (ionospheric physics)

Correspondence to: H. S. S. Sinha

E-mail: hsinha@prl.ernet.in

\section{Introduction and literature review}

One of the most exciting ionospheric phenomena is the occurrence of electron density and electric field irregularities during the equatorial spread $F$ (ESF). ESF is mainly a nighttime phenomenon, created due to post-sunset electrodynamics. The steepening of the bottomside of the $\mathrm{F}$ layer results from the uplift of the $\mathrm{F}$ layer due to the pre-reversal enhancement of the eastward electric field and the loss of ionization by recombination. The steep electron density gradients thus generated are conducive to the growth of electron density and electric field perturbations. These perturbations are produced in wide spatial and temporal scales and manifest as plumes in radar returns, plasma bubbles or depletions in airglow images, ionization holes in the electron density profile obtained through in situ measurements. Various radio, optical and in situ techniques have, therefore, been employed to understand different aspects of irregularities associated with ESF. Ground based observations of coherent VHF radar from Jicamarca (Farley et al., 1970) renewed the interest in this field. The optical techniques which have contributed significantly, include, all sky imagers and scanning photometers for measuring the zonal drift of large-scale irregularities (Mendillo and Baumgardener, 1982; Sinha et al., 1996, Taylor et al., 1997; Tinsley et al., 1997, and references therein). Radio techniques include the coherent backscatter radar, for determining the drift of irregularities and for zonal interferometry (Kudeki et al., 1981); spaced receivers and VHF polarimetry for zonal drifts of irregularities with scale sizes of about a kilometer (Abdu et al., 1985).

In situ probing using the satellite-borne experiments constitutes the direct measurement of horizontal distribution of various parameters, such as plasma drift and phase velocity, through the ion drift meter (IDM) (Aggson et al., 1992; Coley and Heelis, 1989), and plasma drift velocity through the electric field double probes (Jahn et al., 1997). 
In situ probing using the rocket-borne experiments yields the vertical distribution of irregularity parameters. In view of the fact that the atmosphere is nearly horizontally stratified, some of the most important variations are those in the vertical direction. Rocketborne measurements of electron density made earlier, have contributed significantly to our understanding of various processes occurring during ESF. Some of the important results obtained during major $\mathrm{F}$ region rocket campaigns are summarized.

A NASA Javelin rocket was launched from Natal, Brazil, during equatorial spread $\mathrm{F}$ conditions (Kelley et al., 1976). This rocket experiment along with the observations from a $50 \mathrm{MHz}$ radar, provided the first evidence that the regions of depleted plasma density rise due to a buoyancy force and attain altitudes far above the region unstable to the Rayleigh Taylor $(R T)$ instability. This partly explained the high altitude spread F, observed by Farley et al. (1970), in terms of primary instability operating below the peak in $\mathrm{F}$ region electron density $\left(\mathrm{F}_{\text {peak }}\right)$. Costa and Kelley (1978) analyzed the bottom side electron density data, obtained from the same flight, and found that the steepened coherent structures exhibited shallow spectra, with $k^{-2}$ power law behavior in intermediate $(10 \mathrm{~km}>\lambda>100 \mathrm{~m})$ and transitional $(100 \mathrm{~m}>\lambda>10 \mathrm{~m})$ scales instead of a turbulent cascade of structures. Similar $k^{-2}$ power law scaling was observed by Dyson et al. (1974) using AE satellite data, by Morse et al. (1977) in the Equion experiment and also by Kelley and Mozer (1972) using the electric field data. Costa and Kelley (1978) found that sharp density gradients (gradient scale length, $L<100 \mathrm{~m}$ ) could de-stabilize collisional drift waves.

Rino et al. (1981) discussed the fixed-bias Langmuir probe derived electron density power spectra, obtained from Plumex-I rocket, launched from Kwajalein Atoll $\left(9.4^{\circ} \mathrm{N}, 167.45^{\circ} \mathrm{E}\right)$. A fully developed spread $\mathrm{F}$ in decay phase was encountered during this experiment. It was found that for electron density irregularities, with scale sizes ranging between $5 \mathrm{~km}$ and $500 \mathrm{~m}$, the spectral index $(n)$ ranged between -1.2 and -2.5 . However, for irregularities with scale sizes between $50 \mathrm{~m}$ and $500 \mathrm{~m}$, steep spectra was observed with $n$ lying between -2.3 and -3.4 for altitudes less than $370 \mathrm{~km}$. For altitudes greater than $370 \mathrm{~km}$, shallow spectra with $n$ ranging between -1.2 and -2.6 were seen. The break in spectrum observed near $500 \mathrm{~m}$ is a typical dimension for the finger-like striations that have been observed to develop in barium clouds (Keskinen and Ossakow, 1981). The break is evident in data obtained from the vicinity of $F_{\text {peak }}$ and is represented by $n$ flatter than -2 for smaller wave numbers and much steeper than -2 for larger wave numbers. Keskinen and Ossakow (1981) discussed one dimensional bottom side irregularity spectra exhibiting a spectral slope of -2.5 over a scale size range of $1 \mathrm{~km}$ to tens of meters and developed a computational model of $R T$ instability that supported the experimental results.

Kelley et al. (1982a, b) studied Plumex data of electron density as well as electric field fluctuations in different wavelength regimes. They found that density spectra exhibited $k^{-2}$ behavior at long wavelengths and became steeper for $\lambda<100 \mathrm{~m}$ with $n$ around -4.5 or -5 . This spectral form was observed for altitudes higher than $280 \mathrm{~km}$. However, below $280 \mathrm{~km}, k^{-2}$ spectral behavior was observed for scale sizes up to about $20 \mathrm{~m}$. Power spectra of electric field irregularities displayed a Boltzmann relationship for $\lambda<100 \mathrm{~m}$. This was explained in terms of drift waves operating at altitudes above some collisional cut off which was around $280 \mathrm{~km}$. It was suggested that the classical diffusion might also be responsible for a Boltzmann-like relationship between the density and electric field.

Barium-strontium vapor release experiments conducted from SHAR, India, (Raghavarao et al., 1984, 1987), showed the presence of spatial gradients in the electric field around an altitude of $194 \mathrm{~km}$ at the time of onset of ESF, caused by neutral winds and shears in them. Significant vertical winds were also detected at the time of onset time of ESF.

Two sounding rockets instrumented with RF probes and electric field double probes, launched as a part of Condor experiment from Punta Lobos $\left(12.3^{\circ} \mathrm{S}, 76^{\circ} \mathrm{W}\right.$, $0.85^{\circ} \mathrm{N}$ dip), Peru, investigated spread $\mathrm{F}$ depletions. LaBelle et al. (1986) discussed the density and electric field spectra obtained during the Condor campaign. The Condor electron density spectra display a break at a wavelength near $100 \mathrm{~m}$, identical to that found in the PLUMEX experiment (Kelley et al., 1982a, b). Their results were consistent with the previous conjecture that drift waves exist only above $300-\mathrm{km}$ altitude. However, during the Condor experiment, spread $\mathrm{F}$ turbulence was not observed below $280 \mathrm{~km}$ owing to the high altitude of $F$ layer. By dividing the spectra into regions where linear generalized Rayleigh Taylor instability (GRTI) growth is positive (the injection band) and negative (the dissipation band) and then performing an energy balance, they argued that classical ambipolar diffusion accounted for the necessary dissipation for spectra measured at low altitudes. For high altitude spectra, an anomalous diffusion, which is two orders of magnitude stronger than ambipolar diffusion, was needed implying the existence of electrostatic waves. Statistical arguments indicated that the measured spectral forms implied anomalous diffusivity and that this diffusivity was not related to coherent steepening. Thus, diffusion due to wave particle interactions and small-scale drift wave transport seemed likely.

Composite spectra of rocket as well as satellite observations, given by Singh and Szuszczewicz (1984), covered almost six decades of irregularity spatial scales and showed that medium, intermediate and transitional scales are characterized by spectral indices in the range of $-1.5 \pm 0.4,-2.4 \pm 0.2$ and $-4.8 \pm 0.2$, respectively both in the vertical as well as horizontal directions.

Prakash et al. (1991) studied ESF irregularities using RH-560 rockets instrumented with Langmuir probes launched from SHAR, India and found that the relationship between the spectral index, $n$ and the mean integrated spectral power, $P_{T}$, (in $20 \mathrm{~m}$ to $200 \mathrm{~m}$ scale size range) could be represented by a Gaussian function. The altitude variation of $n$, normalized with respect to $P_{T}$, showed that the nature of spectra remains same 
between $230 \mathrm{~km}$ and the apogee of the rocket, which was $332 \mathrm{~km}$. This was at variance with the observation that $280 \mathrm{~km}$ is the threshold altitude for the steep drift wave type of spectra to a shallower spectra (Kelley et al., 1982b).

In situ measurements of electron density and electric field were made from Alcantara, Brazil $\left(2^{\circ} 19^{\prime} \mathrm{S}, 44^{\circ} 22^{\prime} \mathrm{E}\right.$, dip $1.5^{\circ}$ ) during the Guara' campaign (LaBelle et al., 1997; Jahn and LaBelle, 1998). Electron density irregularities in the topside were observed up to $822 \mathrm{~km}$, which was the highest altitude explored so far by rockets and which is also the inertially dominated regime of spread F. Based on the simultaneous coherent backscatter radar observations, it was found that these high altitude electron density structures drift upwards with a speed of about $30 \mathrm{~ms}^{-1}$. It was also inferred that the decay time of spread $\mathrm{F}$ irregularities is independent of scale size (LaBelle et al., 1997). Power spectra of electron density irregularities showed spectral indices of -1.7 and -5 at frequencies less than $60 \mathrm{~Hz}$ and greater than $60 \mathrm{~Hz}$, respectively but the spectra did not show any variation with altitude (Jahn and LaBelle, 1998).

First simultaneous measurements of electron density $\left(n_{e}\right)$ and electric field (EF) fluctuations, in the Indian zone, were made from Sriharikota rocket range, SHAR $\left(14^{\circ} \mathrm{N}, 80^{\circ} \mathrm{E}\right.$, dip lat. $\left.5.5^{\circ} \mathrm{N}\right)$ during a fully developed spread F epoch (Chandra et al., 1997; Sinha et al., 1999). This work presents the results of electron density irregularities and discusses various mechanisms, which are likely to be responsible for their generation.

\section{Flight details}

The RH 560 rocket, carrying the Langmuir probe (LP) and the electric field (EF) payloads, was launched at 2130 LT on 4 October, 1988. The arrangement of sensors on this flight is shown in Fig. 1. Two pairs of the double probes were also used to measure fluctuations in the electric field along and perpendicular to the spin axis of the rocket. Results of electric field measurements have been presented elsewhere (Sinha et al., 1999). A cylindrical, gold plated, LP sensor made of brass was used with a fixed positive bias of 4 volts to measure the current in the electron saturation regime. The LP sensor was mounted on a thin deployable central boom of 25-mm diameter, which was fixed on the top deck of the rocket concentric with its spin axis. The current collected by the sensor was processed onboard in three frequency bands DC-60 Hz, $50-500 \mathrm{~Hz}$, and $125-$ $1250 \mathrm{~Hz}$, which will be referred to as DC, MF and HF channels, respectively. This was done to accommodate the large dynamic range of irregularity amplitude, associated with large scale size range viz., from a few tens of kilometers to about a meter. The LP payload used in this flight was similar to the one described by Prakash and Subbaraya (1967) Prakash et al. (1972), and Sinha (1976). The frequency response of LP system extended to more than a few $\mathrm{KHz}$ enabling the measurement of vertical structures in electron density

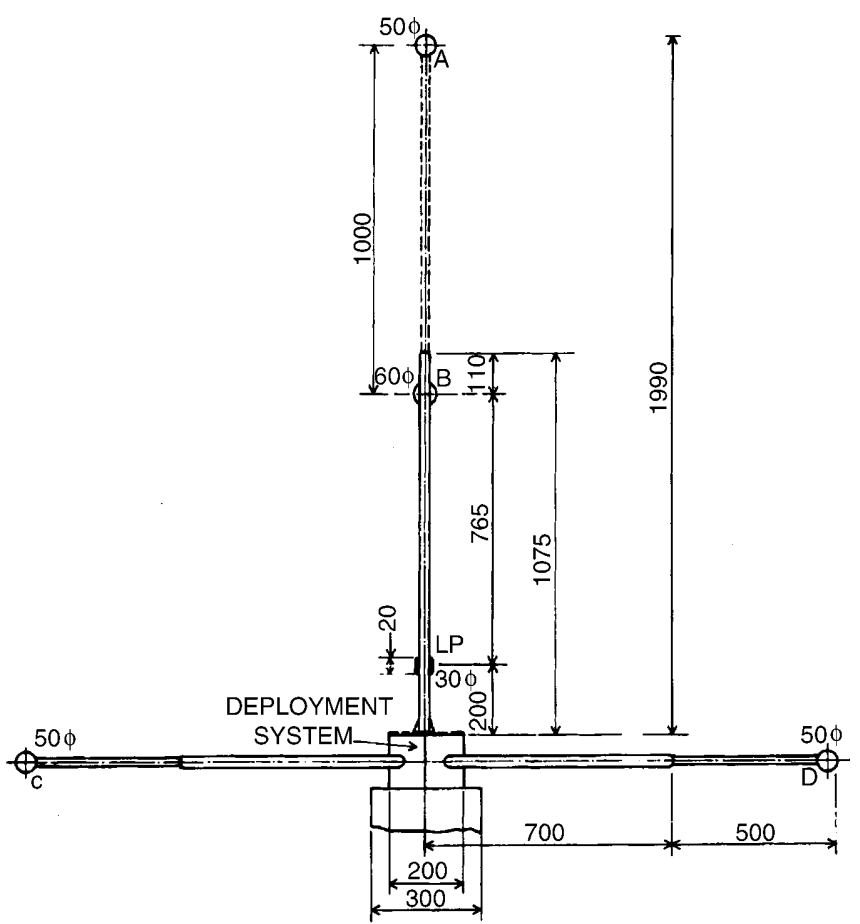

Fig. 1. Geometry of Langmuir probe and electric field sensors flown on the RH-560 rocket from SHAR

with scales as small as one meter. The LP electronics was capable of measuring the current in the range $1 \mathrm{nA}$ to $100 \mu \mathrm{A}$. In order to handle such a large dynamic range of the current, a current to voltage converter with an eight-stage feedback resistance was employed. The probe current was converted into electron density using a fixed calibration factor of 7140 electrons $/ \mathrm{cm}^{-3} / \mu \mathrm{A}$ (Sinha and Prakash, 1995). The rocket, which was launched due east of the SHAR launch station with an elevation of $81.2^{\circ}$ and azimuth of approximately $82^{\circ}$, attained an apogee of $348 \mathrm{~km}$.

\section{Data presentation}

Figure 2 shows the variation of electron density with altitude at 2130 LT on October 4, 1988. The solid and dashed lines show the perturbations in electron density obtained during the rocket ascent and descent, respectively. As the vertical electron density gradients play a very important role in the generation of irregularities, these were calculated from the electron density profile obtained during the ascent of the rocket. Electron density gradient scale length, $L,\left(L^{-1}=\left(1 / n_{e}\right) d n_{e} / d h\right.$; where $d n_{e}$ is the change in electron density over a vertical extent of $d h$ ) was calculated for a vertical extent of $5 \mathrm{~km}$. Such $L$ values were calculated for every $50 \mathrm{~m}$ and the frequency of occurrence of gradients, sharper than an arbitrarily assumed $L^{-1}$ value of $1.0 \mathrm{~km}^{-1}$ was computed over a $1 \mathrm{~km}$ interval.

In addition to the F-region irregularities, this profile shows the presence of two very sharp layers in the E region as well. Electron density irregularities observed in different altitude regions are described later. 


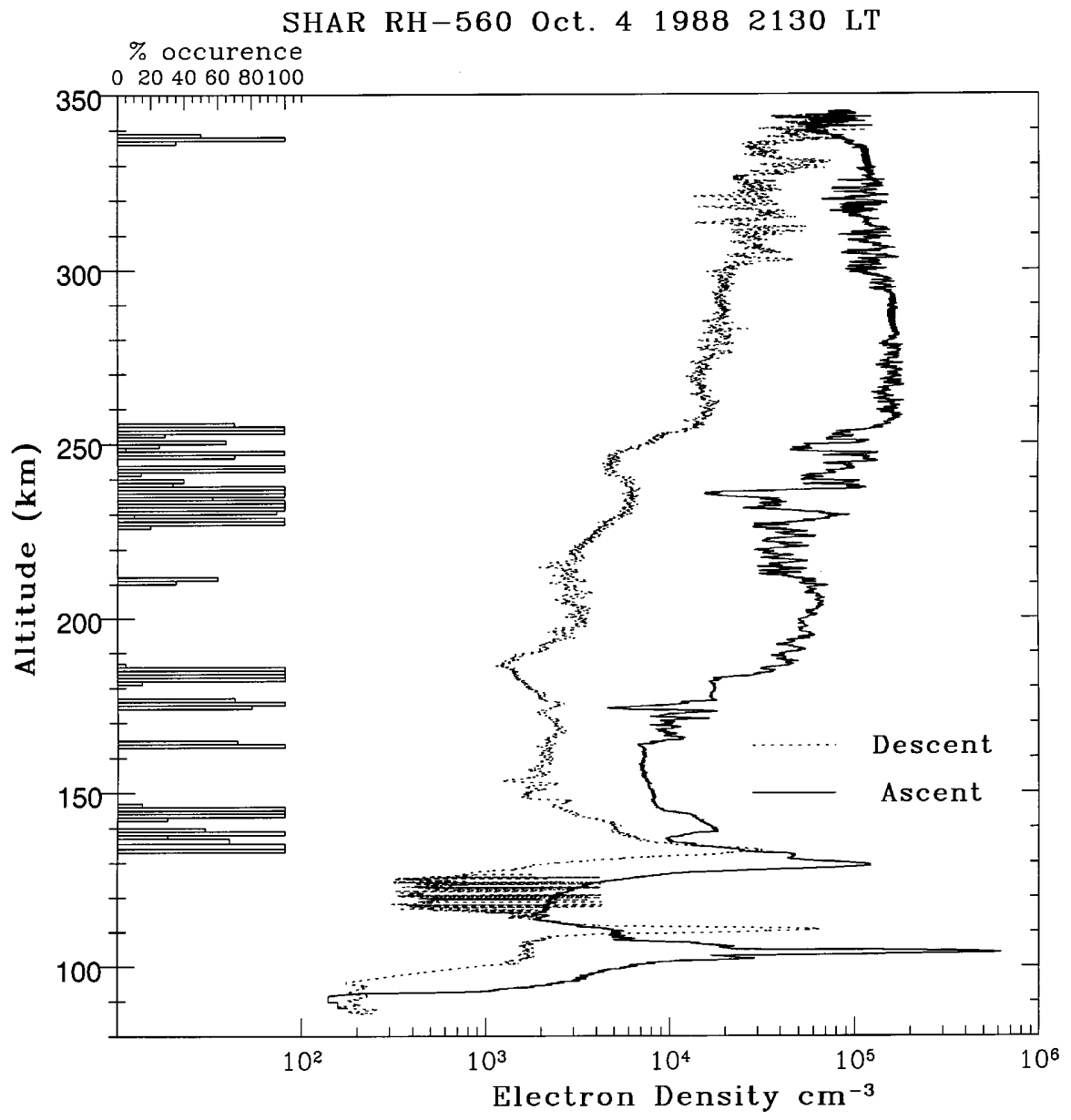

Fig. 2. Variation of electron density with altitude during the ascent and descent of the rocket. Horizontal bars show the percentage occurrence of steep gradients $\left(L^{-1}\right.$ smaller than $1.0 \mathrm{~km}^{-1}$ ) over a vertical extent of $5 \mathrm{~km}$. $L$ values (over $5 \mathrm{~km}$ ) were obtained every $50 \mathrm{~m}$ and the frequency of occurrence of steep gradients in every $1 \mathrm{~km}$ interval (or at 20 points) is plotted

\subsection{Structures below $150 \mathrm{~km}$}

The region below $150 \mathrm{~km}$ displayed large-scale structures, which have a layer-like appearance. Two such sharp layers were observed at 105 and $130 \mathrm{~km}$ during the ascent. In the layer at $105 \mathrm{~km}$, the electron density increased by a factor of 50 in a vertical extent of $10 \mathrm{~km}$ only. Similar structures were observed during descent also but they were located at $110 \mathrm{~km}$ and $135 \mathrm{~km}$, respectively, i.e., about $5 \mathrm{~km}$ higher, vis-à-vis the ascent, indicating the presence of large-scale (over a few hundred kilometers) horizontal gradients in the electron density. At $120 \mathrm{~km}$ altitude, the time interval between ascent and the descent is $460 \mathrm{~s}$ and hence an upward movement of the $F$ layer with a velocity of $11 \mathrm{~ms}^{-1}$ would be required to explain the observation of these peaks at altitudes which are $5 \mathrm{~km}$ higher during the descent. But the actual observed $\mathrm{F}$ layer movement at the time of rocket launch was $20 \mathrm{~ms}^{-1}$ in the downward direction (Chandra et al., 1997). Thus, these sharp layers in the $\mathrm{E}$ region do not appear to be due to temporal effects.

\subsection{Structures between $150 \mathrm{~km}$ and base of the F-region}

A very interesting feature of the electron density profile, is the continuous presence of irregularities from $150 \mathrm{~km}$ to $257 \mathrm{~km}$, which was the base of the $\mathrm{F}$ region. Largescale structures, with vertical scale sizes up to a few tens of $\mathrm{km}$, are also seen in this region. Vertical structures, in the scale size range of $5-10 \mathrm{~km}$, are also quite prominent. The electron density varies significantly in these structures, e.g., by a factor of 5 in a vertical extent of $3 \mathrm{~km}$ around $175 \mathrm{~km}$. Around $184 \mathrm{~km}$, there is an increase in electron density by a factor of 2.5 in a vertical extent of $4 \mathrm{~km}$. Small-scale structures having scale sizes of the order of few hundred meters are also seen, superimposed on large-scale structures in the entire region.

A patch of very intense irregularities can be seen in $210-257 \mathrm{~km}$ region. Irregularities of a range of scale sizes starting from a few hundred meters to a few tens of kilometers are observed in this patch. Around $225 \mathrm{~km}$, scale sizes in the range of a $3-5 \mathrm{~km}$ are quite prominent. The strongest irregularity is seen around $238 \mathrm{~km}$, wherein the electron density is depleted by a factor of 3 in a vertical extent of $4 \mathrm{~km}$. A similar depletion is observed during the descent also, but it is located around $245 \mathrm{~km}$. Percentage amplitude of intermediate irregularities, in the range of $200 \mathrm{~m}-2 \mathrm{~km}$ is observed to be maximum (6\%) in $200 \mathrm{~km}-257 \mathrm{~km}$ region (Fig. 4).

\subsection{Structures above the base of the F-region}

In the region above the base of the $\mathrm{F}$ region $(257 \mathrm{~km})$, strong irregularities are present in two patches lying 
between $257-280 \mathrm{~km}$ and $290-330 \mathrm{~km}$. Although the vertical electron density gradients are practically absent between 260-290 km, small-scale irregularities $(\lambda<1 \mathrm{~km})$ with amplitudes as large as $10 \%$ can be seen in this region. Between $290-330 \mathrm{~km}$ there is a weak gradient of electron density $\left(L^{-1}=-6 \mathrm{~m}^{-1}\right)$ but a large number of small-scale irregularities $(\lambda<2 \mathrm{~km})$, having amplitudes as large as $20 \%$, are seen. Small-scale structures are seen superimposed on the larger ones, throughout the 257$330 \mathrm{~km}$ region, both during the ascent and the descent. The amplitude of slightly larger scale $(\lambda \sim 3-5 \mathrm{~km})$ irregularities is at times as large as $25 \%$ in this region. Percentage amplitude of intermediate irregularities, in the range of $200 \mathrm{~m}-2 \mathrm{~km}$, has a secondary maximum around $312 \mathrm{~km}$ (Fig. 4).

\section{Spectral analysis of irregularities}

The current collected by the LP sensor was processed on board in three frequency channels, viz., DC, MF and the HF channel. For studying intermediate scale irregularities $(100 \mathrm{~m}<\lambda<2 \mathrm{~km})$, data from DC channel was used. Data from MF and HF channels was used for studying the smaller scale size fluctuations. The fast Fourier transform (FFT) technique was used to compute the power spectrum of irregularities. The power spectra of irregularities has been computed in intermediate $(100 \mathrm{~m}-2 \mathrm{~km})$ and transitional $(10 \mathrm{~m}-100 \mathrm{~m})$ scale size ranges using a Hanning window and a data length of about $2 \mathrm{~s}$. A power law of the type $P(k) \propto k^{n}$, where, $P(k)$ is the power spectral density associated with a wave number $k(k=2 \pi / \lambda)$ and $n$ is the spectral index, was used for the computation of the spectral index. Table 1 shows the averaged spectral index over a vertical extent of $10 \mathrm{~km}$ for all the three patches of irregularities.

As shown in Fig. 2, the irregularities were present continuously between 150 and $257 \mathrm{~km}$ and even beyond the base. The most intense irregularities occurred in three patches at $165-178 \mathrm{~km}, 210-257 \mathrm{~km}$ and 290 $330 \mathrm{~km}$. Power spectra of irregularities at three representative altitudes, for each of these three patches, are shown in Fig. 3.

Table 1. Variation of spectral index, ' $n$ ' with altitude for the intermediate and transitional scale electron density irregularities

\begin{tabular}{lll}
\hline $\begin{array}{l}\text { Altitude } \\
(\mathrm{km})\end{array}$ & $\begin{array}{l}\text { Intermediate Scale } \\
(100 \mathrm{~m}-2 \mathrm{~km})\end{array}$ & $\begin{array}{l}\text { Transitional Scale } \\
(10 \mathrm{~m}-100 \mathrm{~m})\end{array}$ \\
\hline $165 \pm 5$ & -3.78 & -3.99 \\
$215 \pm 5$ & -3.83 & -4.47 \\
$225 \pm 5$ & -3.81 & -4.62 \\
$235 \pm 5$ & -3.38 & -4.07 \\
$245 \pm 5$ & -3.43 & -4.18 \\
$255 \pm 5$ & -3.28 & -3.29 \\
$265 \pm 5$ & -3.86 & -3.50 \\
$275 \pm 5$ & -3.88 & -3.29 \\
$295 \pm 5$ & -3.11 & -2.72 \\
$305 \pm 5$ & -3.70 & -3.27 \\
$315 \pm 5$ & -3.21 & -3.38 \\
$325 \pm 5$ & -2.75 & -3.29 \\
\hline
\end{tabular}

Spectra at 169 and $172 \mathrm{~km}$ show a spectral peak corresponding to $2-\mathrm{km}$ scale size, whereas no such peak is present at $176 \mathrm{~km}$ (Fig. 3a). The strongest irregularities on this flight were observed in $210-257 \mathrm{~km}$ region. Power spectra of these irregularities at three representative altitudes $(224,246$ and $278 \mathrm{~km})$ are shown in Fig. $3 \mathrm{~b}$. The spectrum at $278 \mathrm{~km}$ shows a peak corresponding to about $0.9 \mathrm{~km}$ scale size, similar to what is seen at 169 and $172 \mathrm{~km}$. Power spectra for three sample cases (291, 314 and $330 \mathrm{~km}$ ), within the third patch, are shown in Fig. 3c. All the three spectra have spectral peaks in the intermediate range. The location of the peak is at $1 \mathrm{~km}, 630 \mathrm{~m}$ and $240 \mathrm{~m}$ at 291, 314 and $330 \mathrm{~km}$, respectively. The spectrum at $330 \mathrm{~km}$ shows a secondary peak at $110 \mathrm{~m}$ also.

The average spectral index of transitional scales for 160-178 km, 210-250 km, 250-280 km and 290-330 km regions is $-3.99,-4.33,-3.36$ and -3.17 , respectively. As seen in Fig. 3, there is no indication of any break in the spectrum, within the transitional scale, at higher altitudes $(290-330 \mathrm{~km})$.

\section{Estimation of linear growth rate of intermediate scales}

It is believed that the primary mechanism for the generation of intermediate scale irregularities is the generalized Rayleigh-Taylor instability (GRTI) (Dungey, 1956; Haerendel, 1974; Hudson and Kennel, 1975; Scannapieco and Ossakow, 1976; Keskinen et al., 1981; Zalesak et al., 1982). This primary instability generates horizontal gradients on which secondary instabilities can operate giving rise to a wide spectrum of irregularities. The expression for the growth rate of perturbations by GRTI (Eq. 1) includes the contributions from the gradient drift instability (through the electric field term), Rayleigh Taylor instability (through the gravitational term) and neutral winds (Kelley et al., 1981). It is known that the gravitational term is unstable whenever $\mathbf{g}$ has a component anti-parallel to the electron density gradient and the local linear growth rate, $\gamma_{g}$, is given by $\gamma_{g}=g /\left(v_{i n} L\right)$, where $v_{i n}$ is the ion-neutral collision frequency and $L$ is the gradient scale length. The gradient drift instability operates when $\mathbf{E} \times \mathbf{B}$ is parallel to $\nabla n_{e}$ and the local linear growth rate due to the electric field, $\gamma_{\mathrm{E}}$, is given by $\gamma_{\mathrm{E}}=\mathrm{E} / \mathrm{BL} \cdot \gamma_{\mathrm{E}}$ is, in general, less than $\gamma_{g}$ for altitudes above $300 \mathrm{~km}$. Thus, during the post-sunset period, a westward electric field can make the bottom side of the $\mathrm{F}$ region unstable, if a downward electron density gradient is present.

In presence of winds and electric fields, the current density, $\mathbf{j}$ is given by $\mathbf{j}=\sigma \mathbf{E}^{\prime}$, where $\sigma$ is conductivity and $\mathbf{E}^{\prime}=\mathbf{E}+\mathbf{U} \times \mathbf{B}(\mathbf{U}$ and $\mathbf{B}$ represent neutral winds and magnetic field, respectively). As the large-scale neutral wind is primarily eastward at sunset (Sipler and Biondi, 1978), $(\mathbf{U} \times \mathbf{B}) \times \mathbf{B}$ is also horizontal and hence cannot have a component parallel to $\nabla n_{e}$, if the ionosphere is horizontally stratified. Sekar and Raghavarao (1987) studied the role of vertical winds on growth rate of the collisional $R-T$ instability in the linear 


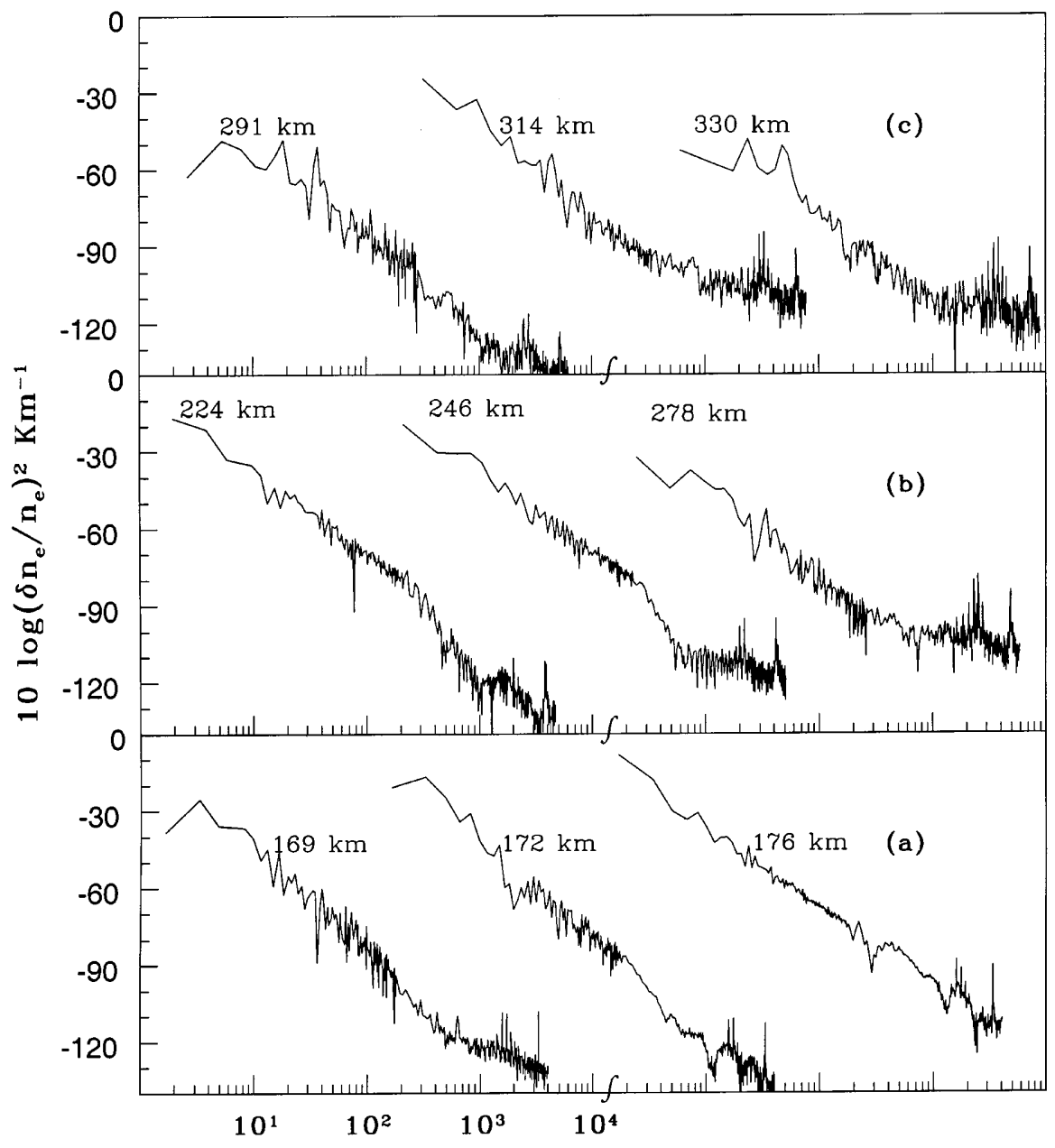

Fig. 3a-c. Power spectra of electron density irregularities in a large scale size range, covering intermediate, transitional and short scales, at three representative altitudes a 169 , 172 and $176 \mathrm{~km}$ in the Valley region, $\mathbf{b}$ at 224, 246 and $278 \mathrm{~km}$ which lie near and below the F-region base and $\mathbf{c}$ at 291, 314 and $330 \mathrm{~km}$ which is the region below the F-peak. Each spectrum represents an altitude range of $2 \mathrm{~km}$

\section{Wavenumber $\mathrm{km}^{-1}$}

regime. They found that the effect of vertically downward wind can be more effective than the gravitational term in triggering the instability in the altitude region of $200-300 \mathrm{~km}$. The effective linear growth rate of the irregularities generated through GRT instability including vertical winds, $\gamma_{g}$ can be written as:

$\gamma_{g}=\frac{\mathrm{E} \cos \alpha}{\mathrm{B} L}+\frac{g \cos \alpha}{v_{i n} L}+\frac{\mathrm{U} \sin \alpha}{L}+\frac{W}{L}+v_{R}$

where, $W$ is the vertical wind, $\alpha$ is the tilt of the ionosphere and $v_{R}$ is the recombination coefficient.

Growth rate estimates, for intermediate scale irregularities observed during this flight, are made using observed electron density gradients, to discuss the contribution of different agencies in producing these irregularities. For estimating the linear growth rate of the electron density irregularities in the scale size range of $100 \mathrm{~m}$ to $2 \mathrm{~km}$, which lies in the intermediate scale, electron density gradient scale length, $L$, was calculated over $5 \mathrm{~km}$ vertical interval, as mentioned earlier. In view of the fact that downward vertical winds $(W)$ in the range of $10-25 \mathrm{~ms}^{-1}$ have been observed earlier over SHAR (Raghavarao et al., 1984, 1987; Sridharan et al., 1997), a vertically downward wind of $20 \mathrm{~ms}^{-1}$ was considered realistic, and the same has been used here, for the calculation of linear growth rate. Horizontal neutral winds $(\mathbf{U})$ were not required as the calculations were made for a horizontal ionosphere, i.e., the tilt was assumed to be zero. The electric field has been estimated from the movement of $\mathrm{F}$ layer as seen in the ionosonde data taken at SHAR at the time of present rocket flight (Chandra et al., 1997). At the time of this flight, the F layer was moving downward with a velocity of $20 \mathrm{~ms}^{-1}$, which corresponds to westward electric field of about $0.8 \mathrm{mV} / \mathrm{m}$. The recombination coefficient, $v_{R}$, has been taken from McFarland et al., (1973) and $v_{\text {in }}$ has been computed using the expression $v_{\text {in }} \approx 2.4 \times 10^{-11} M^{-1 / 2} n_{n}$, where $n_{n}$ is the neutral density and $M$ is the mean molecular weight of the neutrals and ions (Kelley, 1989). These neutral parameters have been taken from the mass spectrometer incoherent scatter (MSIS-86) model. The estimated $\gamma_{g}$ for the $n_{e}-h$ profile obtained on October 4, 1988 is shown in Fig. 4. Also shown in the last panel of this figure is the percentage amplitude of irregularities with scale sizes $(200 \mathrm{~m}-2 \mathrm{~km})$. The middle panel displays the smoothed profile (obtained by taking a $4 \mathrm{~km}$ running average) for viewing large-scale structures. It shows strong kinks in electron density around $235 \mathrm{~km}$ and $245 \mathrm{~km}$ and lack of large-scale perturbations between 250 to $290 \mathrm{~km}$. However, smaller kinks 


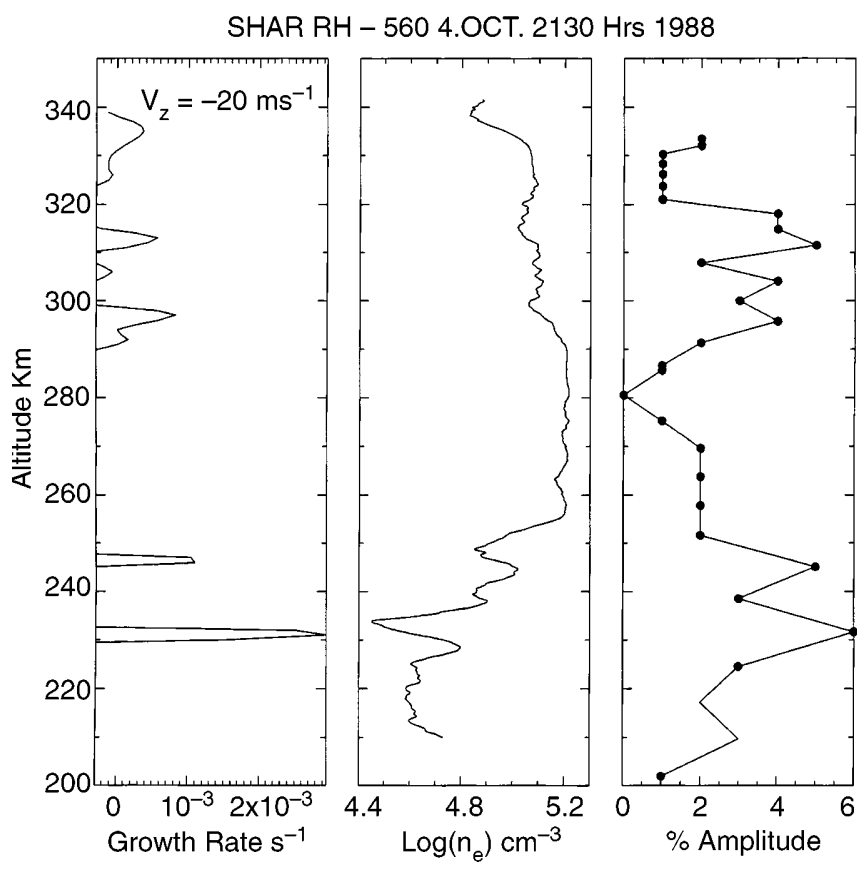

Fig. 4. The altitude variation of linear growth rate of irregularities generated through GRT instability is shown in the first panel, the middle panel shows the electron density profile obtained by taking a $4 \mathrm{~km}$ running average of the actual profile during the ascent and the last panel shows the percentage amplitude of the irregularities in the intermediate scale $(200 \mathrm{~m}-2 \mathrm{~km})$

are observed between $292-320 \mathrm{~km}$ also. It can be clearly seen, from the last panel of Fig. 3, that the amplitude of $200 \mathrm{~m}-2 \mathrm{~km}$ irregularities is maximum $(6 \%)$ around $232 \mathrm{~km}$, around which the smoothed profile exhibits the largest kink. At other altitudes, the growth rate of irregularities is appreciable, wherever, the large-scale gradients are prominent. This is in agreement with the consensus that hierarchy of processes operate where large-scale irregularities can give rise to smaller scale irregularities (Haerendel, 1974). The effective growth rate is maximum $\left(\gamma_{\text {eff }} \approx 2.9 \times 10^{-3} \mathrm{~s}^{-1}\right)$ around $232 \mathrm{~km}$, which coincides with the region where the profile displays strong irregularities in the intermediate scale. It is seen that $\gamma_{\text {eff }}$ is positive at altitudes where the amplitude is appreciable supporting the belief that they are produced by the GRTI mechanism.

Figure 2 shows the percentage occurrence of strong electron density gradients during the ascent, which are shown as horizontal bars, along with electron density profiles. It is seen that percentage occurrence of strong gradients is maximum $(\sim 80 \%)$ around $236 \mathrm{~km}$ and near the apogee i.e, around $345 \mathrm{~km}$ and these are co-located with strong irregularities occurring in the same altitude range. The base of the $\mathrm{F}$ layer is located around $257 \mathrm{~km}$ and the bottom side of the $\mathrm{F}$ layer is characterized by $L \sim 7.6 \mathrm{~km}$ where electron density increases by a factor of $6.1 \mathrm{in} 10 \mathrm{~km}$ altitude extent.

The relationship between the growth rate, $\gamma_{g}$ and the gradient scale length, $L$, has also been investigated. Figure 5 shows a plot of strong gradients $\left(+0.27 \mathrm{~km}^{-1}\right.$ $>L^{-1}>-0.1 \mathrm{~km}^{-1}$ ) and the growth rate at the corresponding altitude for $200-330 \mathrm{~km}$ region. It can be seen

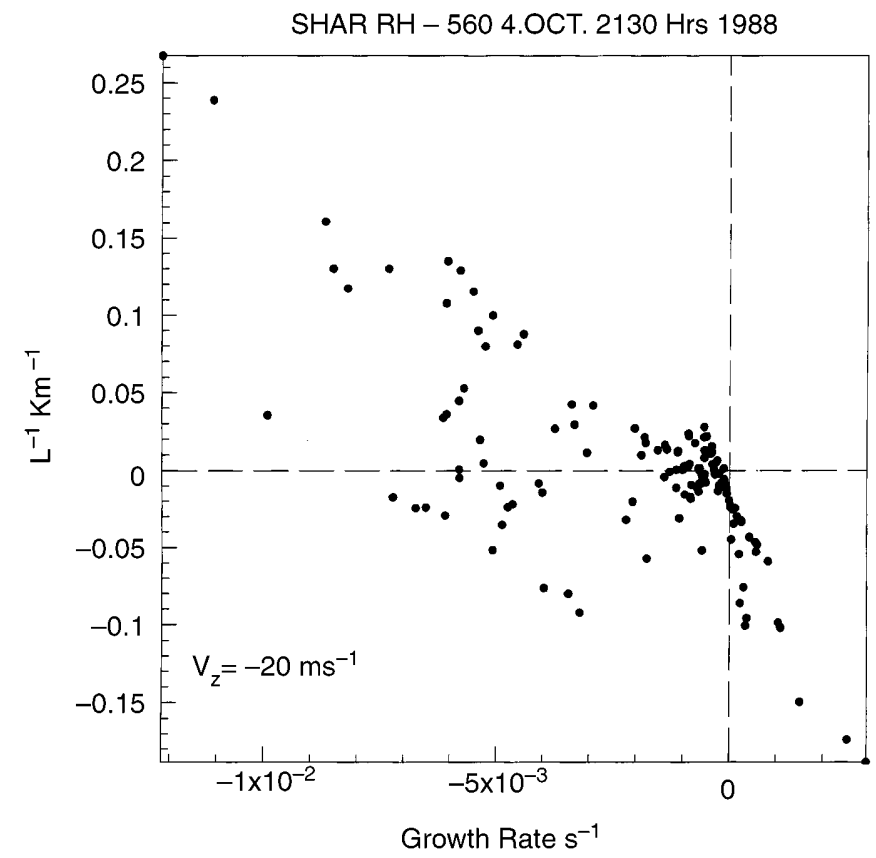

Fig. 5. Relationship between the effective linear growth rate, $\gamma_{g}$, and the inverse gradient scale length, $L^{-1}$ for altitude range of $200-330 \mathrm{~km}$. A vertically downward wind $\left(V_{z}\right)$ of $20 \mathrm{~ms}^{-1}$ was used for the calculation of the growth rate

from Fig. 5 that the growth rate is positive only when the electron density gradients are negative.

\section{Discussion}

\subsection{Large-scale irregularities}

The detection of two very sharp layers of electron density in 105-130 $\mathrm{km}$ region, both during the ascent and descent, is a new observation. Such large increase of electron density, by a factor of 50 in a $10 \mathrm{~km}$ interval, has not been reported in the literature, so far. Earlier rocket flights from SHAR (Prakash et al., 1991) showed a number of large-scale structures in the region 100 $150 \mathrm{~km}$ with vertical scale sizes up to $25 \mathrm{~km}$, but the electron density increase in such layers was only by a factor of 20 or less. The E-region flight from Thumba, reported by Prakash et al. (1970), revealed the presence of layered structures with scale sizes of 5-10 km in 90$130 \mathrm{~km}$ altitude region but the electron density increase in these structures was only by a factor of 10 or less. Based on the halfwidth of these layers $(5-10 \mathrm{~km})$, it appears that the internal gravity waves could be one plausible source for the generation of these sharp layers. Some modeling work on the generation of such sharp layers by gravity wave winds would be able to confirm the role of gravity waves in the generation of such sharp layers.

During the ascent, the layers were observed at 105 and $130 \mathrm{~km}$, while during the descent they were observed at 110 and $135 \mathrm{~km}$. The horizontal separation between the ascent and descent, at $135 \mathrm{~km}$ and $110 \mathrm{~km}$ altitudes, is about $300 \mathrm{~km}$ and $310 \mathrm{~km}$, respectively. 
Shifting of these peaks to higher altitudes during the descent, cannot be due to the movement of $F$ layer also, because at the time of rocket launch (2130 LT), the F layer was observed to be moving downwards with a velocity of $20 \mathrm{~ms}^{-1}$ (Chandra et al., 1997). The observation of both these layers during the rocket descent, at altitudes which were about $5 \mathrm{~km}$ higher than those during the ascent, indicates the presence of large-scale horizontal gradients in electron density.

Another very interesting observation from the present data is regarding two regions around $175 \mathrm{~km}$ and $238 \mathrm{~km}$, where, the strongest decreases in electron density were detected. The decreases can be seen very clearly in the descent data also, but their locations were at slightly higher altitudes (at $187 \mathrm{~km}$ and $245 \mathrm{~km}$ respectively). The horizontal separation between the ascent and descent at $180 \mathrm{~km}$ and $240 \mathrm{~km}$ is $273 \mathrm{~km}$ and $230 \mathrm{~km}$, respectively. Assuming a nighttime zonal plasma drift of $150 \mathrm{~ms}^{-1}$, it can be inferred that the depletions encountered during the rocket ascent and descent cannot be the same. The presence of these two structures at different altitudes during the ascent and descent indicates the presence of horizontal gradients in the electron density distribution. In addition to these two prominent structures, the entire electron density profile points towards the existence of very strong horizontal electron density gradients. The strongest horizontal gradient appears around $210 \mathrm{~km}$, where the electron densities are $6 \times 10^{4} \mathrm{~cm}^{-3}$ and $3 \times 10^{3} \mathrm{~cm}^{-3}$, respectively, during the ascent and descent, i.e., the descent values were down by a factor of 20 compared to the ascent. The horizontal separation between the ascent and descent at $210 \mathrm{~km}$ is about $240 \mathrm{~km}$. It is important to note that both the profiles are very close to each other below about $130 \mathrm{~km}$ indicating that the probe does not come in the wake of the rocket during the descent. Large horizontal gradients in electron density have been reported by Sobral et al. (1997) during a non-spread F period for an equatorial station Alcantara $\left(2^{\circ} 19^{\prime} \mathrm{S}\right.$, $\left.44^{\circ} 22^{\prime} \mathrm{W}\right)$. Sobral et al. (1997) found the change in electron density by a factor of about 2 at $230 \mathrm{~km}$ altitude. The difference in ascent and descent values is likely to be much enhanced during a spread $\mathrm{F}$ event. Thus, the present observations, which were conducted during a well-developed spread $\mathrm{F}$ epoch, showing maximum change in electron density by a factor of 20 around $210 \mathrm{~km}$ altitude, indicate the presence of enhanced horizontal electron density gradients throughout the $150-300 \mathrm{~km}$ altitude region during fully developed spread F. Similar horizontal gradients were observed by McClure et al. (1977), in AE satellite data. Recently, Gdalevich et al. (1998) reported the presence of horizontal gradients in plasma density, using a cylindrical Langmuir probe in the rocket experiment 'Vertical-10', and attributed these to large-scale disturbances propagating as internal gravity waves (IGWs), in the upper atmosphere.

As mentioned before, large-scale structures with vertical scale sizes, of about a few tens of kilometers, are also seen in the valley region which extends down to about $130 \mathrm{~km}$. It is interesting to note that the earlier observations of electron density from SHAR revealed a smooth density profile in this region (Prakash et al., 1991). The presence of such large-scale structures in our data, point to the possibility that gravity waves might be playing a role in generating irregularities in this region. Horizontal motions, obtained from 25 sodium vapor release experiments, were examined in the altitude range from 70-190 km, by Kochanski (1964). The weakest vertical wind shears, in the $70-190 \mathrm{~km}$ altitude range, were observed in a quiescent region, occurring between $140-190 \mathrm{~km}$. This region was characterized by a few sheared structures having half wavelengths of $20-25 \mathrm{~km}$. Gravity waves having such scale sizes are permissible at these altitudes by the theory of the internal gravity waves (Hines, 1960), which allows only large scales in this region. Hydrodynamic considerations allow a wide spectrum of these waves at any altitude above $50 \mathrm{~km}$ but certain modes are removed by viscous dissipation, reflection and viscosity. As a consequence, the dominant modes attain their maximum amplitude in the $\mathrm{E}$ region and only a very small fraction of these waves reaches the base of the F layer. At $90 \mathrm{~km}$ the empirically found vertical wavelength of the dominant modes is $12 \mathrm{~km}$, horizontal wavelength is around $600 \mathrm{~km}$, and the time scale of the motion is in the range of 1-2 $h$. The theory does not specify dominant modes but sets lowest permissible limits, vertical wavelength over $1 \mathrm{~km}$ are allowed at heights near $100 \mathrm{~km}$ and over $80 \mathrm{~km}$ at the altitude $180 \mathrm{~km}$. Horizontal motions are predominant and vertical motions are estimated to be less than $10 \%$ of horizontal components. The role of gravity waves in producing seed irregularities in the $\mathrm{F}$ region has recently been emphasized by Prakash (1996, 1999), who invoked a new mechanism for the production of irregularities through E-region gravity wave winds.

\subsection{Intermediate scale irregularities}

The present observations show the presence of very strong irregularities in the valley region $(165-178 \mathrm{~km})$. As shown in Fig. 3, the spectra at 169 and $172 \mathrm{~km}$ exhibit a spectral peak at about 2-km scale size, whereas the spectrum at $176 \mathrm{~km}$ does not show any such peak. The average spectral index of intermediate scale irregularities in $160-170 \mathrm{~km}$ region was found to be -3.78 . At these low altitudes the growth rate of irregularities due to $R T$ instability would be very small, owing to high ion-neutral collision frequencies. Such steep spectral indices at such low altitudes can not be explained by the gradient drift instability also.

Irregularities in the F-region valley, as reported, have been observed earlier only on a very few occasions. Woodman and LaHoz (1976) first identified valley region irregularities below the main plumes in the RTI radar maps obtained from Jicamarca. Vickrey et al. (1984) studied electron density irregularities observed in the $\mathrm{F}$ region valley, which were obtained from fixed bias LP flown on two rockets launched from Natal, Brazil (Kelley et al., 1976, 1979; Costa and Kelley, 1978) and from Kwajalein Atoll (Szuszczewicz et al., 1980, 1981; 
Rino et al., 1981; Kelley et al., 1982b). During these two flights quasi-sinusoidal fluctuations in the $\mathrm{F}$ region valley $(170$ to $200 \mathrm{~km}$ ) were observed where the local zero order vertical plasma density gradient nearly vanishes. Vickrey et al. (1984) showed that the spectra in this region displayed peaks at wavelengths of 700 to $1400 \mathrm{~m}$ and proposed a simple steady state theory to explain the formation of structures in the $F$ region valley. It was suggested that the valley region irregularities were the 'images' of irregularities produced by the GRT instability operating in the bottom side of the F layer at the equator. The image striation theory of Vickrey et al. (1984) predicted a scale size-dependent effective diffusion process in the $\mathrm{F}$ region that dominates over classical cross-field diffusion at kilometer scales. The irregularities at 169 and $172 \mathrm{~km}$, observed here, were also seen in the in situ electric field observations on the same flight (Sinha et al., 1999) and can be explained in terms of the image striation theory of Vickrey et al. (1984).

The spectrum of irregularities at $176 \mathrm{~km}$, however, does not show any peak at kilometer scales, both in the electron density and electric field (Sinha et al., 1999), and hence can not be explained in terms of the image striation theory. As such steep spectral indices of the irregularities in this altitude region $(176 \mathrm{~km})$ has not been observed earlier, this is an interesting feature and it appears that some new mechanism has to be invoked for explaining these irregularities.

As shown in Fig. 4, the intermediate range irregularities $(100 \mathrm{~m}-2 \mathrm{~km})$ were observed in abundance in altitude regions $220-250 \mathrm{~km}$ and $290-320 \mathrm{~km}$. In the lower (upper) region the amplitude was maximum around $232 \mathrm{~km}(311 \mathrm{~km})$. The amplitude of these irregularities is found to have a strong correlation with the electron density gradient. The percentage occurrence of large-scale gradients (over $5 \mathrm{~km}$ vertical extent) was maximum ( $~ 80 \%)$ around $236 \mathrm{~km}$ (Fig. 2). As shown in the middle panels of Fig. 4, the electron density gradients over slightly smaller scales $(<2 \mathrm{~km})$ are present in the upper altitude range (290-320 km). Corresponding to these small-scale gradients, one can clearly see the presence of smaller scales (within the intermediate scales) in the upper region. Computation of the effective linear growth rate, of intermediate scale irregularities, produced through the GRT instability, was made using the in situ observed parameters and an assumed realistic vertical wind (Fig. 4). The computed growth rate maximizes around 232 and $310 \mathrm{~km}$, the altitudes around which the irregularities are observed to have maximum amplitude. As the growth rate of GRTI is positive in regions of negative electron density gradients (Fig. 5), these observations point that $R T$ instability was not operating in this case. At lower altitudes $v_{i n}$ is more and hence $R T$ instability will be less dominating than the gradient drift instability and winds in contrast to the higher altitudes. The direction of electric field, as inferred from the motion of the F layer, was westward, which would be conducive to the growth of irregularities, through gradient drift instability, only if, the gradients are negative. Thus, it appears that during this flight, the gradient drift instability was responsible for the generation of irregularities in the intermediate scales both at lower and as well as at higher altitudes.

The spectral indices of the irregularities, given in Table 1 , can be represented by $-3.4 \pm 0.5$. These spectral index values, though slightly higher than those reported by Rino et al. (1981), can be interpreted in terms of GRT instability. Thus the intermediate irregularities, observed over SHAR, appear to be generated through GRT instability and the dominant contribution to the growth is by gradient drift instability and not by $R T$ instability.

\subsection{Transitional and short-scale irregularities}

The irregularities in the transitional scale are present in plenty, in $220-250 \mathrm{~km}$ and $290-330 \mathrm{~km}$ regions, where the electron density decreases with increasing altitude, i.e., a negative density gradient region. As shown in Fig. 2, these irregularities are stronger in the upper region as compared to the lower region. The spectra of transitional scales are quite steep in the lower region having an average spectral index of -4.32 (Table 1). The spectra of transitional scales do not show any break in spectrum. The gradient drift instability could be one of the mechanisms for the generation of the irregularities in the lower as well as upper regions. The spectral nature of irregularities in the upper region is too steep for the turbulent cascade and too shallow for gradient driven drift waves and hence needs further study. Evidence for shorter scale phenomena, observed above $210 \mathrm{~km}$, also requires further study.

\section{Summary}

A new and the most important finding of the present in situ measurements of the electron density is the detection of two very sharp layers of ionization at $105 \mathrm{~km}$ and $130 \mathrm{~km}$. The electron density in these layers increased by a factor of 50 in a vertical extent of just $10 \mathrm{~km}$. The mechanism of generation of these sharp layers is not known. Some possibility of the role of gravity waves has been conjectured based on the scale sizes involved but this has to be examined more rigorously.

In addition to these sharp layers, two very prominent electron density depletions were also observed at $175 \mathrm{~km}$ and $238 \mathrm{~km}$ during the ascent of the rocket. Both sharp layers and depletions, were observed during the descent of the rocket also but their location was about $5 \mathrm{~km}$ higher as compared to the ascent. Based on the actual observations of the $\mathrm{F}$ layer movement, it has been shown that shifting of these features to higher altitudes during the descent cannot be due to the movement of the $F$ layer. These features unambiguously show the existence of very significant horizontal electron density gradients at the time of fully developed spread F. Largescale horizontal gradients in electron density during non-spread $\mathrm{F}$ period have been observed earlier (McC- 
lure et al., 1977; Sobral et al., 1997; Gdalevich et al., 1998). These gradients, which were much weaker than the ones reported here, were attributed to large-scale disturbances propagating as internal gravity waves (Gdalevich et al., 1998).

Some of the valley region irregularities (at $169 \mathrm{~km}$ and $172 \mathrm{~km}$ ) in the intermediate scale size range, show spectral peaks around $2 \mathrm{~km}$. These irregularities are shown to be the images of irregularities in the bottom side of the equatorial $F$ layer produced by GRT instability as suggested by Vickrey et al. (1984). The irregularities at $176 \mathrm{~km}$ reported here do not exhibit any peak at kilometer scale sizes and hence can not be explained in terms of the image striation theory. These irregularities appear to be of a new type.

Electron density irregularities in intermediate, transitional and short scale size range were observed very prominently in three patches $(165-178 \mathrm{~km}, 210-257 \mathrm{~km}$ and $290-330 \mathrm{~km}$ ). Calculations of linear growth rate of intermediate scale sizes produced by GRT instability, using the actual electron density and an assumed vertically downward wind of $20 \mathrm{~ms}^{-1}$, suggest that these irregularities could be produced by gradient drift instability and not by the $R T$ instability. Spectral indices of intermediate scales were found to be in a range of $-3.4 \pm 0.5$. Transitional scale irregularities were observed in $220-250 \mathrm{~km}$ and $290-330 \mathrm{~km}$ region. Spectra of these irregularities were observed to be slightly steeper in $220-250 \mathrm{~km}$ region but did not show any break.

Acknowledgements. The authors thank Professors S. Prakash, H. Chandra and Mr. R.N. Misra for their help in conducting the rocket flight. Authors are grateful to the staff of Vikram Sarabhai Space Center (VSSC), Trivandrum and Shriharikota rocket range (SHAR) for providing all the necessary facilities for this rocket flight. This work was supported by the Physical Research Laboratory, Ahmedabad.

The Editor-in-chief thanks three referees for their help in evaluating this paper.

\section{References}

Abdu, M. A., I. J. Kantor, I. S. Batista, and E. R. de Paula, Eastwest bubble irregularity motion determined from spaced VHF polarimeters: Implications on velocity shear in the zonal $\mathrm{F}$ region bulk plasma motion, Radio Sci., 20, 1, 111-122, 1985.

Aggson, T. L., W. J. Burke, N. C. Maynard, W. B. Hanson, W. R. Hogey, and J. L. Saba, Electric field observations of equatorial bubbles, J. Geophys. Res., 97, 2997, 1992.

Chandra, H., G. D. Vyas, H. S. S. Sinha, S. Prakash, and R. N. Misra, Equatorial spread F campaign over SHAR, J. Atmos. Sol. Terr. Phys., 59, 191, 1997.

Coley, W. R., and R. A. Heelis, Low latitude zonal and vertical ion drifts seen by DE 2, J. Geophys. Res., 94, 6751, 1989.

Costa, E., and M. C. Kelley, On the role of the steepened structures and drift waves in equatorial spread F, J. Geophys. Res., 83, 4359-4364, 1978.

Dungey, J. W., Convective diffusion in the equatorial $\mathrm{F}$ region, J. Atmos. Terr. Phys., 9, 304-310, 1956.

Dyson, P. L., J. P. McClure, and W. B. Hanson, In situ measurements of the spectral characterstics of $\mathrm{F}$ region ionospheric irregularities, J. Geophys. Res., 79, 1497-1502, 1974.
Farley, D. T., B. B. Balsey, R. F. Woodman, and J. P. McClure, Equatorial spread F: implications of VHF radar observations, J. Geophys. Res., 75, 7199-7216, 1970.

Gdalevich, G. L., V. F. Gubsky, N. I. Izhovkina, and V. D. Ozerov, Observation and theory of topside ionospheric plasma inhomogeneities, J. Atmos. Solar Terr. Phys., 60, 247-252, 1998.

Haerendal, G., Theory of equatorial spread-F, Report, MaxPlanck-Institut. fur. Phys. Und. Astrophys., Garching, West Germany, 1974.

Hines, C. O., Internal atmospheric gravity waves at ionospheric heights, Can. J. Phys., 38, 1441-1481, 1960.

Hudson, M. K., and C. F. Kennel, Linear theory of equatorial spread F, J. Geophys. Res., 80, 4581-4590, 1975.

Jahn, J.-M., and J. LaBelle, Rocket measurements of high-altitude spread $\mathrm{F}$ irregularities at the magnetic dip equator, J. Geophys. Res., 103, 23 427, 1998.

Jahn, J.-M., J. LaBelle, and R. F. Pfaff, DC electric field measurements with the Guara spread F rocket, Geophys. Res. Lett., 24, 1695-1698, 1997.

Kelley, M. C., The earth's ionosphere, in Plasma physics and electrodynamics, Academic Press, San Diego, Calif, 1989.

Kelley, M. C., and F. S. Mozer, A satellite survey of vector electric fields in the ionosphere at frequencies of 10 to $500 \mathrm{~Hz}$, J. Geophys. Res., 77, 4183, 1972.

Kelley, M. C., K. D. Baker, and J. C. Ulwick, Late time barium cloud striations and their possible relationship to equatorial spread F, J. Geophys. Res., 84, 1898, 1979.

Kelley, M. C., G. Haerendal, H. Kappler, A. Valenzuela, B. B. Balsley, D. A. Carter, W. L. Ecklund, C. W. Carlson, B. Hausler, and R. Torbert, Evidence for a Rayleigh-Taylor type instability and upwelling of depleted density regions during equatorial spread F, Geophys. Res. Lett., 3, 448-450, 1976.

Kelley, M. C., M. F. Larson, C. Lahoz, and J. P. McClure, Gravity wave initiation of Equatorial spread F: a case study, J. Geophys. Res., 86, 9087-9100, 1981.

Kelley, M. C., R. C. Livingston, C. L. Rino, and R. T. Tsunoda, The vertical wave number spectrum of topside equatorial spread $F$ : estimates of backscatter levels and implications for a unified theory, J. Geophys. Res., 87, 5217, 1982 a.

Kelley, M. C., R. Pfaff, K. D. Baker, J. C. Ulwick, R. C. Livingston, C. L. Rino, and R. T. Tsunoda, Simultaneous rocket probe and radar measurements of equatorial spread F: Transitional and short wavelength results, J. Geophys. Res., 87, 1575-1588, 1982b.

Keskinen, M. J., and S. L. Ossakow, On the spatial power spectrum of the $\mathbf{E} \times \mathbf{B}$ gradient drift instability in ionospheric plasma clouds, J. Geophys. Res., 86, 6947, 1981.

Keskinen, M. J., E. P. Szuszczewicz, S. L. Ossakow, and J. C. Holmes, Nonlinear theory and experimental observations of the local collisional Rayleigh-Taylor instability in a descending Equatorial spread F ionosphere, J. Geophys. Res., 86, 57855792, 1981.

Kochanski, A., Atmospheric motions from sodium cloud drift, J. Geophys. Res., 69, 3651-3662, 1964.

Kudeki, E., B. G. Fejer, D. T. Farley, and H. M. Lerkic, Interferometer studies of equatorial $\mathrm{F}$ region irregularities and drifts, Geophys. Res. Lett., 8, 377, 1981.

LaBelle, J., M. C. Kelley, and C. E. Seyler, An analysis of the role of drift waves in equatorial spread F, J. Geophys. Res., 91, 5513-5525, 1986.

LaBelle, J., J.-M. Jahn, R. F. Pfaff, W. E. Swartz, J. H. A. Sobral, M. A. Abdu, P. Muralikrishna, and E. R. dePaula, The Brazil/ Guara equatorial spread F campaign: results of large scale measurements, Geophys. Res. Lett., 24, 13, 1691-1694, 1997.

McFarland, M., D. L. Albritton, F. C. Fehsenfeld, E. E. Furguson, and A. L. Schmeltekopf, Flow-drift technique for ion mobility and ion-molecule reaction rate constant measurements. II. Positive ion reactions of $\mathrm{N}^{+}, \mathrm{O}^{+}$, and $\mathrm{N}_{2}{ }^{+}$with $\mathrm{O}_{2}$ and $\mathrm{O}^{+}$ with $\mathrm{N}_{2}$ from thermal to $\sim 2 \mathrm{eV}$, J. Chem. Phys., 59, 6620-6628, 1973. 
McClure, J. P., W. B. Hanson, and J. F. Hoffman, Plasma bubbles and irregularities in the equatorial ionosphere, J. Geophys. Res., 82, 2650-2656, 1977.

Mendillo, M., and J. Baumgardener, Airglow characteristics of equatorial plasma depletions, J. Geophys. Res., 87, 7641, 1982.

Morse, F. A., B. C. Edgar, H. C. Koons, C. J. Rice, W. J. Heikkila, J. H. Hoffman, R. F. Woodman, J. Pomalaza, and N. R. Teixeira, Equion, an equatorial ionospheric irregularity experiment, J. Geophys. Res., 82, 578-592, 1977.

Prakash, S., Generation of perturbation electric fields suitable for triggering of equatorial spread-F by gravity waves in the Eregion and zonal winds in the F-region, Indian J. Rad. Space Phys., 25, 211-277, 1996.

Prakash, S., Production of electric field perturbations by gravity wave winds in the $\mathrm{E}$ region suitable for initiating equatorial spread F, J. Geophys. Res., 104, 10 051-10 069, 1999.

Prakash, S., and B. H. Subbaraya, Langmuir probe for the measurement of electron density and electron temperature in the ionosphere, Rev. Sci. Inst., 38, 1132-1136, 1967.

Prakash, S., S. P. Gupta, and B. H. Subbaraya, A study of the irregularities in the night time equatorial $\mathrm{E}$ region using a Langmuir probe and plasma noise probe, Planet Space Sci., 18, 1307, 1970.

Prakash S., B. H. Subbaraya, and S. P. Gupta, Rocket measurements of ionization irregularities in the equatorial ionosphere at Thumba and identification of plasma instabilities, Ind. J. RDA. Space Phys., 1, 72-80, 1972.

Prakash, S., S. Pal, and H. Chandra, In-situ studies of equatorial spread F over SHAR-steep gradients in the bottomside F-region and transitional wavelength results., J. Atmos. Terr. Phys., 53, 977-986, 1991.

Raghavarao R., J. N. Des, B. G. Anandarao, R. Narayanan, R. Sekar, Ranjan Gupta, V. V. Babu, and V. Sudhakar, Evidence for the large scale electric field gradient at the onset of equatorial spread F, J. Atmos. Terr. Phys., 46, 355-362, 1984.

Raghava Rao R., S. P. Gupta, R. Sekar, R. Narayanan, J. N. Desai, R. Sridharan, V. V. Babu, and V. Sudhakar, In-situ measurements of wind, electric fields and electron densities at the onset of equatorial spread F, J. Atmos. Terr. Phys., 49, 485-492, 1987.

Rino, C. L., R. T. Tsunoda, J. Petriceks, R. C. Livington, M. C. Kelley, and K. D. Baker, Simultaneous rocket-borne beacon and in situ measurements of equatorial spread F, J. Geophys. Res., 86, 2411, 1981.

Scannapieco, A. J., and S. L. Ossakow, Non-linear equatorial spread F, Geophys. Res. Lett., 3, 451-454, 1976.

Sekar, R., and R. Raghavarao, Role of vertical winds on the Rayleigh-Taylor instability mode of the nightime equatorial ionosphere, J. Atmos. Terr. Phys., 49, 981-985, 1987.

Singh, M., and E. P. Szuszczewicz, Composite equatorial spread F wave number spectra from medium to short wavelengths, J. Geophys. Res., 89, 2313, 1984.
Sinha, H. S. S., Studies in equatorial aeronomy, PhD Thesis, Gujarat University, Ahmedabad, India, 1976.

Sinha, H. S. S., and S. Prakash, Electron densities in the equatorial lower ionosphere over Thumba and SHAR, Ind. J. Rad. Space Phys, 24, 184-192, 1995.

Sinha, H. S. S., R. N. Misra, H. Chandra, S. Raizada, N. Dutt, and G. D. Vyas, Multi-wavelength optical imaging of ionospheric plasma depletions, Ind. J. Rad. Space Phys., 25, 44-52, 1996.

Sinha, H. S. S., S. Raizada, and R. N. Misra, First simultaneous in situ measurement of electron density and electric field fluctuations during spread $\mathrm{F}$ in the Indian zone, Geophys. Res. Lett., 20, 1669-1672, 1999.

Sipler, D. P., and M. A. Biondi, Equatorial F region neutral winds from nightglow OI $630.0 \mathrm{~nm}$ Doppler shifts, Geophys. Res. Lett., 5, 373-376, 1978.

Sobral, J. H. A., M. A. Abdu, P. Muralikrishna, H. Takahashi, H. S. Sawant, C. J. Zamlutti, and M. G. de Aquino, Horizontal gradients of the nocturnal OI $557.7 \mathrm{~nm}$ and OI $630 \mathrm{~nm}$ photoemission rates in the equatorial ionosphere based on rocket electron density data, Adv. Space Res., 20, 1317, 1997.

Sridharan, R., H. Chandra, S. R. Das, R. Sekar, H. S. S. Sinha, D. Pallam Raju, R. Narayanan, S. Raizada, R. N. Misra, R. Raghavarao, P. B. Rao, P. V. S. Ramarao, V. V Somayajulu, V. V. Babu, and A. D. Danilov, Ionisation hole campaign- a coordinated rocket and ground based study at the onset of equatorial spread-F: first results, J. Atmos. Terr. Phys., 59, 16, 2051-2067, 1997.

Szuszczewicz, E. P., R. T. Tsunoda, R. Narcisi, and J. C. Holmes, Coincident radar and rocket observations of equatorial spread F, Geophys. Res. Lett., 7, 537-540, 1980.

Szuszczewicz, E. P., R. T. Tsunoda, R. Narcisi, and J. C. Holmes, Plumex II: a second set of coincident radar and rocket observations of equatorial spread F, Geophys. Res. Lett., 8, 803-806, 1981.

Taylor, M. J., J. V. Eccles, J. LaBelle, and J. H. A. Sobral, High resolution OI $(630 \mathrm{~nm})$ image measurements of F-region depletion drifts during the Guará campaign, Geophys. Res. Lett., 24,(13), 1699-1702, 1997.

Tinsley, B. A., R. P. Rohrbaugh, and W. B. Hanson, Images of transequatorial $\mathrm{F}$ region bubbles in $630-$ and $777-\mathrm{nm}$ emissions compared with satellite measurements, J. Geophys. Res., 102,(A2), 2057-2077, 1997.

Vickrey, J. F., M. C. Kelley, R. Pfaff, and S. R. Goldman, Lowaltitude image striations associated with bottomside equatorial spread F: observations and theory, J. Geophys. Res., 89, 2955, 1984.

Woodman, R. F., and C. LaHoz, Radar observations of F region equatorial irregularities, J. Geophys. Res., 81, 5447-5466, 1976.

Zalesak, S. T., and S. L. Ossakow, and P. K. Chaturvedi, Nonlinear equatorial spread F: the effects of neutral winds and background Pederson conductivity, J. Geophys. Res., 87, 151-166, 1982. 